Sports Science

\title{
Can a genetic profile be related to performance in young talent track and field athletes? A pilot study
}

\author{
Pamela C. Da Rosa ${ }^{1}$ (D), Gustavo Oneda ${ }^{1}$ (D), Larissa B. Daros ${ }^{2,4}$ (D), Antônio C. Dourado ${ }^{2}$ (D), \\ Daniele Sartori $^{3}$ (D), Danilo F. Leonel ${ }^{1}$ (D), Crystina L.B.P. Bara ${ }^{1}$ (D), Raul Osiecki ${ }^{1}$ \\ ${ }^{1}$ Universidade Federal do Paraná, Departamento de Educação Física, Centro de Estudos da \\ Performance Física, Curitiba, PR, Brazil; ${ }^{2}$ Universidade Estadual de Londrina, Departamento de \\ Ciências do Esporte, Londrina, PR, Brazil; ${ }^{3}$ Universidade Estadual de Londrina, Departamento \\ de Bioquímica e Biotecnologia, Londrina, PR, Brazil; ${ }^{4}$ Universidade Estadual do Centro-Oeste \\ do Paraná, Guarapuava, PR, Brazil.
}
Associate Editor: Dustin Jay Oranchuk (D), Auckland University of Technology, Sports
Performance Research Institute New Zealand, Sprinz, New Zealand. E-mail:
dustinoranchuk@gmail.com.

\begin{abstract}
Aim: This study analyzed the influences of ACE and ACTN3 gene variants in sprinters, jumpers, and endurance young athletes of track and field. Methods: 36 school-level competitors of both sex (15 girls and 21 boys; aged $16.4 \pm 1.2$ years; training experience $4 \pm 1.2$ years) practitioners of different sport disciplines (i.e., sprint, jump, and endurance athletes) participated in the study. The deoxyribonucleic acid (DNA) was extracted from peripheral blood using a standard protocol. Anthropometric measurements, $30 \mathrm{~m}$ sprint, squat jump (SJ), and maximal oxygen uptake $\left(\mathrm{VO}_{2 \max }\right)$ tests were measured. Results: Genotype distribution of the ACE and ACTN3 genes did not differ between groups. In ACE DD and ACTN3 RX genotypes, the SJ test was bigger in sprinters and jumpers than in the endurance runners. In contrast, when analyzing the ACE ID genotype, sprinters had higher SJ than endurance athletes. Moreover, in the ACE DD genotype, the sprinters and jumpers' athletes had lower time in $30 \mathrm{~m}$ tests compared to endurance runners. However, the ACE ID and ACTN3 RX genotypes was greater aerobic fitness in endurance runners than in jumpers' athletes. Conclusion: Although the genetic profile is not a unique factor for determining athletic performance, the ACE DD and ACTN3 RX genotypes seem to favor athletic performance in power and sprint versus endurance sports. Thus, this study evidenced that assessing genetic variants could be used as an auxiliary way to predict a favorable profile for the identification of young talents of track and field.
\end{abstract}

Keywords: ACE, ACTN3, sport, talent.

\section{Introduction}

Genetic variants have an important influence over determinants of athletic performance, such as endurance, strength, power, neuromuscular coordination, size, and composition of muscle fiber ${ }^{1}$. Furthermore, recent research has shown considerable evidence of a significant association between genetic and optimal environmental conditions, it seems to exert an important role in certain types of sport phenotypes ${ }^{2}$. The complex interactions concerning athletic potential are related to the synergy of several physiological and psychological factors, combined with external factors including nutritional status, altitude, training, and socioeconomic factors ${ }^{3}$.

Different genetic markers have been explored to identify important polymorphisms and genetic variants with the potential to predict successful elite sport ${ }^{4,5}$. The most promising gene in that regard is ACTN3, which has commonly been associated with strength, speed, power, and endurance performance ${ }^{6,7}$. Studies reported that ACTN3 is a gene that encodes for $\alpha$-actinin-3, present only in type-II muscle fibers. A common genetic variation in the ACTN3 gene results in a cytosine-to-thymine replacement transforms the arginine base (R) to a premature stop codon (X) at amino-acid 577 , whose carrier of the RR homozygotes and the $\mathrm{R}$ allele may be related to muscle size and strength, faster race times and a higher proportion of type II muscle fibers ${ }^{8}$. Another important gene for athletic performance is the ACE, it regulates blood pressure, and therefore has an essential role in cardio-respiratory efficiency. The ACE can also influence skeletal muscle function and growth factors involved in overloadinduced muscle hypertrophy ${ }^{9-13}$. The most studied polymorphism of this gene is an insertion-deletion polymorphism (I/D) that has been associated with 
endurance sports performance (allele I) and strength/ power (allele D) $)^{14}$.

Nevertheless, little is known about talent identification and genotype-phenotype relationships to predict future sporting success based on young athletes. Current findings contradict existing potential relationships between the prevalence of ACE DD homozygotes, and consequently a better performance of young soccer players in sprint test ${ }^{15}$. Whereas studies suggest there is no association between the ACE and ACTN3 genes, individually or in combination, for muscle strength/power in Polish-trained athletes of different disciplines. This finding suggests that both epigenetic and environmental factors act as a key regulator of athletic performance ${ }^{16}$. On the other hand, it is also important to emphasize that RR, $\mathrm{RX}$, and DD genotypes benefit athletes in strength and speed tasks, while ACE II homozygotes provide bigger fitness in endurance athletes, although there are environmental interactions that may influence sport performance $^{17}$.

A recent review showed that both ACE and ACTN3 genes can predict elite athletic capability to take into account multifactorial factors, as athletic training ${ }^{18}$. Therefore, if there are possibilities to trace a favorable genetic profile combined with an ideal training environment, it can be used to predict future athletic potential. Moreover, talent detection programs using genetic have been an integral part of the process of building elite athletes. However, the set of variables that can predict a sporting talent and its subsequent success, is still unclear for many sports organizations ${ }^{19}$.

In this way, we hypothesized that there may be specific genetic variants that could be associated with better results for sprinters, jumpers, and endurance athletes. Thus, the purpose of this pilot study was based on the need to assess the feasibility of the ACE and ACTN3 gene variants on muscle power, speed, and endurance tasks; particularly in young talent track and field athletes.

\section{Methods}

\section{Participants and experimental design}

The sample consisted of 36 track and field athletes of both sexes ( 15 girls, 21 boys; aged $16.4 \pm 1.2$ years; training experience $4 \pm 1.2$ years) engagement in the Olympic talent program. All participants were chosen as the best school-level athletes in their sports discipline by state sports federations. All athletes won their sport discipline medals in the 2016 school championships. Written consent was obtained from each subject and his/her responsible. The study was complied with the Declaration of Helsinki and was approved by the national ethics committee (CONEP 5231).
Different sport disciplines enabled us to divide the participants into three athletic groups (sprint, jump, and endurance runners). The sprint group comprised 11 athletes $(4$ girls, 7 boys; aged $16.1 \pm 1.4$ years; height $171 \pm 7.8 \mathrm{~cm}$; weight $59.9 \pm 9.24 \mathrm{~kg}$; fat mass $8.2 \pm 3.94 \%$; training experience $3.9 \pm 1.28$ years) from the following sport disciplines: sprints $100-400 \mathrm{~m}(\mathrm{n}=6)$ and 100-400 m hurdles $(\mathrm{n}=5)$. The jumping group comprised 14 athletes ( 8 girls, 6 boys; aged $16.7 \pm 1.4$ years; height $171 \pm 7.3 \mathrm{~cm}$; weight $59.63 \pm 6.6 \mathrm{~kg}$; fat mass $11.16 \pm 4.56 \%$; training experience $4.5 \pm 1.11$ years) from the following sport disciplines: pole vault $(\mathrm{n}=3)$, long jump $(n=5)$, high jump $(n=3)$, and triple jump $(n=3)$. The endurance group comprised 11 athletes ( 3 girls, 8 boys; aged $16.1 \pm 0.87$ years; height $169 \pm 8.9 \mathrm{~cm}$; weight $58.16 \pm 6.15 \mathrm{~kg}$; fat mass $8.48 \pm 6.99 \%$; experience $3.66 \pm 1.41$ years) from the following sport disciplines: middle-distance 800-1500 m ( $\mathrm{n}=3)$, long-distance 3000$5000 \mathrm{~m}(\mathrm{n}=5)$ and $2000 \mathrm{~m}$ steeplechase $(\mathrm{n}=3)$. The experimental design is shown in Figure 1.

\section{Blood collection and genotype assessment}

Blood samples were collected from the antecubital vein into $4 \mathrm{~mL}$ tubes with ethylenediamine tetraacetic acid (EDTA). Peripheral blood mononuclear cells (PBMCs) were separated from whole blood by density gradient centrifugation with a Histopaque ${ }^{-1077}$ solution (SigmaAldrich, St. Louis, USA), as previously described ${ }^{20}$. Then, the DNA was isolated from PBMCs pellets according to the phenol-chloroform method.

The I/D polymorphism of ACE was determined as previously described ${ }^{21}$. The $\mathrm{D}$ and I alleles were identified using polymerase chain reaction (PCR) amplification of the respective fragments from intron 16 of the ACE gene and size fractionation and visualization by electrophoresis. The primers for intron 16 were as follows: hace $3 \mathrm{~s} 5^{\prime}$ TGGGACCACAGCGCCCGCCACTAC 3 ' e hace 3 as $5^{\prime}$

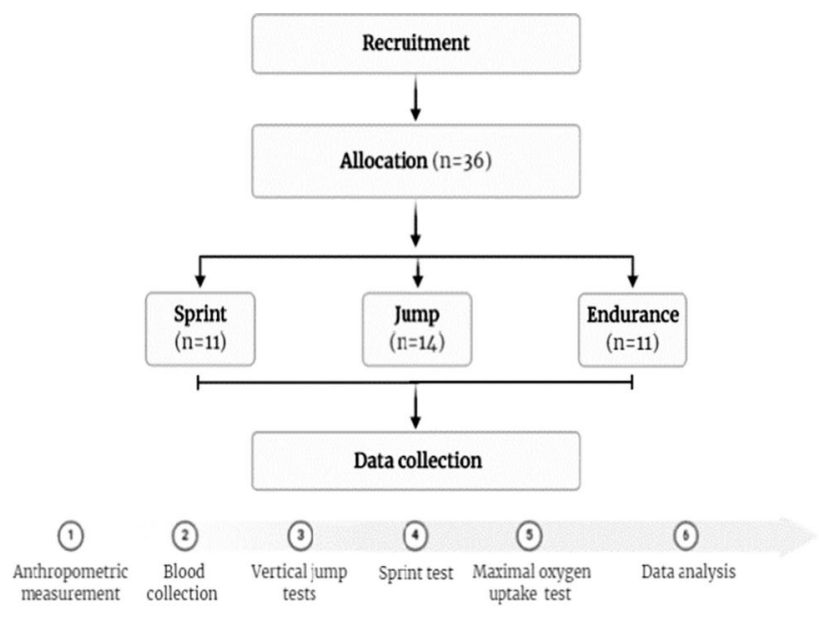

Figure 1 - Illustration of the experimental design. 
TCGCCAGCCCTCCCATGCCCATAA 3'. The PCR was performed in a $\mathrm{T} 100^{\mathrm{TM}}$ Thermal Cycler (BioRad) consisting of initial denaturation at $94{ }^{\circ} \mathrm{C}$ for $5 \mathrm{~min} ; 35$ cycles of $94{ }^{\circ} \mathrm{C}$ for $30 \mathrm{~s}, 56{ }^{\circ} \mathrm{C}$ for $45 \mathrm{~s}, 72{ }^{\circ} \mathrm{C}$ for $2 \mathrm{~min}$ and final extension at $72{ }^{\circ} \mathrm{C}$ for $7 \mathrm{~min}$. The PCR product was analyzed by electrophoresis $1 \%$ using Quantum ST4 (Biosystems). This method yields 318 and $597 \mathrm{bp}$ fragments for D and I alleles, respectively.

Because the $\mathrm{D}$ allele in heterozygous samples is preferentially amplified ${ }^{22}$, PCR amplifications were also performed with an I-specific primer pair $\left(5^{\prime}\right.$ TGGGACCACAGCGCCCGCCACTAC $3^{\prime}$ and $5^{\prime}$ TCGCCAGCCCTCCCATGCCCATAA 3') as previously described $^{21}$, with identical PCR conditions except for an annealing temperature of $67^{\circ} \mathrm{C}$. The reaction yields a $335 \mathrm{bp}$ amplicon only in the presence of an I allele, and no product in samples homozygous for DD.

The R577X polymorphism of ACTN3 was typed using a TaqMan SNP Genotyping Assay (Assay ID: rs1815739; Applied Biosystems, Foster City, CA, USA), and the reaction was performed in a CFX96 Touch $^{\mathrm{TM}}$ Real-Time PCR Detection System (BioRad). The genotyping mixture (total of $10 \mu \mathrm{L}$ ) contained $10 \mu \mathrm{l}$ of TaqMan Universal Master Mix, $1 \mu \mathrm{l}$ of assay mix, genomic DNA $(100 \mathrm{ng} / \mu \mathrm{L})$, and $7 \mu \mathrm{L}$ of ultra-pure water for each reaction. The PCR was performed by initial denaturation at $95^{\circ} \mathrm{C}$ for $5 \mathrm{~min} ; 40$ cycles at $94{ }^{\circ} \mathrm{C}$ for $10 \mathrm{~s}, 60^{\circ} \mathrm{C}$ for $15 \mathrm{~s}$; and a final extension at $72{ }^{\circ} \mathrm{C}$ for $10 \mathrm{~s}$. The results were analyzed using CFX Manager software (BioRad).

\section{Phenotype assessment}

Anthropometric measurement

Height $(\mathrm{cm})$ was evaluated by a standardized protocol. Weight ( $\mathrm{kg}$ ), fat mass (\%), and fat-free mass (\%) were assessed by an air displacement plethysmograph (BOD POD Gold Standard Body Composition Tracking System).

Vertical jump test

SJ tests were performed using a platform Jumptest ${ }^{\circledR}$ model (Hidrofit Ltda., Brazil) as reported previously ${ }^{23}$. At the starting position, subjects kept both hands on the hips and reached $90^{\circ}$ of knee flexion angle, and then, the subjects performed a vertical jump. The test was performed three times (each separated by a 1 min rest period) and the best score was retained.

Sprint test

Subjects performed the $30 \mathrm{~m}$ sprint test using a photoelectric cell (Multi Sprint ${ }^{\mathrm{TM}}$, Hidrofit ${ }^{\circledR}$ ) as previously described $^{24}$. The sprint test involves running a maximum sprint over $30 \mathrm{~m}$, with the time recorded. The $30 \mathrm{~m}$ tests were performed two times (each separated by a $5 \mathrm{~min}$ rest period) and the best time was registered.
$\mathrm{VO}_{2 \max }$ test

The maximal incremental test was assessed on the treadmill (Inbramed 10.500 ATL, Porto Alegre, Brazil) using a Cosmed $\mathrm{K} 4 \mathrm{~b}^{2}$ portable gas analysis system. Participants started exercising at a treadmill speed of $7 \mathrm{~km} \cdot \mathrm{h}^{-1}$ and an incline of $1 \%$ gradient for $3 \mathrm{~min}$. After, the workload was subsequently increased by $1 \mathrm{~km} \cdot \mathrm{h}^{-1}$ each minute until exhaustion as previously described ${ }^{25}$.

\section{Statistical analysis}

The Shapiro-Wilk test was used to confirm the normality of quantitative variables. With normal data distribution, a one-way analysis of variance (ANOVA), followed by Tukey's Test for post-hoc comparison. A $\chi^{2}$ test was used to compare genotype frequencies between athletes from different disciplines. Significance was set at $p<0.05$, and continuous data were expressed as the mean and standard deviation of the mean (SD), while categorical data were expressed as a percentage. The Eta-Squared $\left(\eta^{2}\right)$ was estimated to reveal the effect sizes for a betweengroups ANOVA and classified as small $\left(\eta^{2}=0.01\right)$, medium $\left(\eta^{2}=0.059\right)$, and large $\left(\eta^{2}=0.138\right)$ effects. Statistical analysis was performed using GraphPad (version 8.0 for Macintosh OSX, GraphPad Software, San Diego, CA).

\section{Results}

Our data showed only three subjects with XX polymorphism, however, but did not find with II polymorphism. Moreover, the sample size presented within groups with XX polymorphism was small; $\mathrm{n}=1$ in each group (i.e., sprint, jump, and endurance runners). For these reasons, we have decided that it is not possible to report.

There was no difference in anthropometric measurement and training experience among the athletes of sprint, jump, and endurance. The results of the genotypes distribution did not differ between groups for ACTN3 $\left(\chi_{(4)}^{2}=4.489 ; \mathrm{p}=0.334\right)$ or $\mathrm{ACE}\left(\chi_{(4)}^{2}=0.257\right.$; $\mathrm{p}=0.880)($ see Table 1$)$.

Figure 2 illustrates the effects of ACE and ACTN3 gene variants on SJ test. In DD genotype, analysis showed

Table 1 - Distribution of ACTN3 and ACE genes in each group.

\begin{tabular}{lccccc}
\hline & & \multicolumn{3}{c}{ Group } & Overall \\
\cline { 3 - 5 } & & Sprint & Jump & Endurance \\
\hline \hline ACE & DD & $4(11.1 \%)$ & $4(11.1 \%)$ & $3(8.3 \%)$ & $11(30.6 \%)$ \\
& DI & $7(19.4 \%)$ & $10(27.8 \%)$ & $8(22.2 \%)$ & $25(69.4 \%)$ \\
& Overall & $11(30.6 \%)$ & $14(38.9 \%)$ & $11(30.6 \%)$ & $36(100.0 \%)$ \\
ACTN3 & RR & $7(19.4 \%)$ & $4(11.1 \%)$ & $3(8.3 \%)$ & $14(38.9 \%)$ \\
& RX & $3(8.3 \%)$ & $9(25.0 \%)$ & $7(19.4 \%)$ & $19(52.8 \%)$ \\
& Overall & $10(30.6 \%)$ & $13(38.9 \%)$ & $10(30.6 \%)$ & $33(100.0 \%)$ \\
\hline
\end{tabular}

Different letters indicate significant differences between groups (oneway test (ANOVA) followed by Tukey's test, $\mathrm{p}<0.05$ ). 

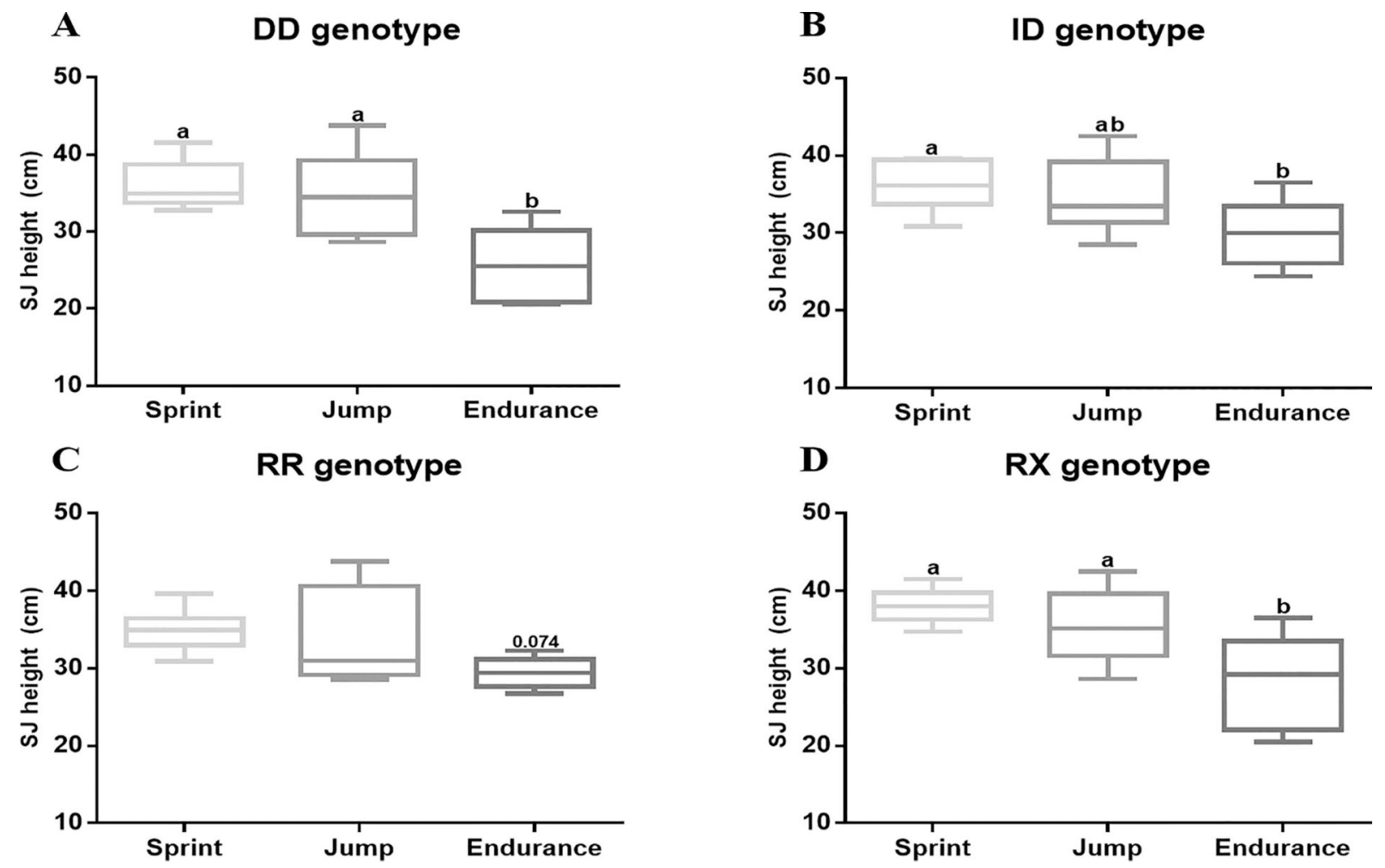

Figure 2 - Effect of ACE and ACTN3 gene variants on SJ in young talents. The DD genotype (a), ID genotype (b), RR genotype (c) and RX genotype (d). Different letters indicate significant differences between groups (one-way test (ANOVA) followed by Tukey's test, $\mathrm{p}<0.05$ ).

a higher SJ performance in the sprinters and jumpers when compared to endurance athletes $\left(\mathrm{F}_{(2,12)}=6.928 ; \mathrm{p}=0.01\right.$; $\eta^{2}=.53$ ) (Figure 2a), while in ID genotype was showed increase SJ in sprinters when compared to endurance $\left(\mathrm{F}_{(2,21)}=4.913 ; \mathrm{p}=0.017 ; \eta^{2}=.31\right)$ (Figure $\left.2 \mathrm{~b}\right)$. Moreover, in ACTN3 RX genotype, lower performance of the SJ was observed in the endurance when compared to the other groups $\left(\mathrm{F}_{(2,20)}=7.821 ; \mathrm{p}=0.003 ; \eta^{2}=.43\right)$ (Figure 2d). However, there were no differences in RR genotype $\left(\mathrm{F}_{(2.14)}=3.137 ; \mathrm{p}=0.074 ; \eta^{2}=.30\right)$ between groups (Figure 2c).

Figure 3 illustrates the effects of ACE and ACTN3 gene variants on the $30 \mathrm{~m}$ sprint test. In the DD genotype, sprinters and jumpers had lower time in $30 \mathrm{~m}$ when compared to endurance $\left(\mathrm{F}_{(2,12)}=8.886 ; \mathrm{p}=0.0043 ; \mathrm{\eta}^{2}=.59\right)$ (Figure 3a), while the ID (Figure 3b), RR (Figure 3c), and RX (Figure 3d) genotypes did not shown significant difference.

Figure 4 shows the effects of ACE and ACTN3 gene variants on $\mathrm{VO}_{2 \max }$. The endurance group with $\mathrm{ID}\left(\mathrm{F}_{(2,21)}\right.$ $\left.=8.925 ; \mathrm{p}=0.0016 ; \mathrm{\eta}^{2}=.45\right)($ Figure $4 \mathrm{~b})$ and $\mathrm{RX}\left(\mathrm{F}_{(2,18)}\right.$ $=5.501 ; \mathrm{p}=0.013 ; \eta^{2}=.37$ ) (Figure $4 \mathrm{~d}$ ) genotypes show higher aerobic fitness when compared to jumpers athletes. However, no changes in $\mathrm{VO}_{2 \max }$ were observed among the groups with DD (Figure 4a) and RR (Figure 4c) genotypes.

\section{Discussion}

Our main results showed that both ACE and ACTN3 gene variants seem to exert potential effects on the athletic performance of jumpers, sprinters, and endurance athletes, specifically in young talents of track and field. The DD homozygotes and RX heterozygotes, particularly at the sprinters and jumpers had better SJ scores than in endurance running. Indeed, the D allele has been associated with a greater percentage of fibers type IIb/x (i.e., glycolytic/fast-twitch type $)^{26}$, while $\mathrm{R}$ allele generates a functional $\alpha$-actinin- 3 that is almost exclusively expressed in fast glycolytic fibers (IIx), which appears to have an advantage for speed and power tasks ${ }^{27,28}$. A higher number of RX heterozygotes expressing the $\alpha$-actinin- 3 protein was observed at sprinters compared to endurance athletes $^{6}$. Consistent with our hypothesis, the DD and RX variants showed better results for sprinters and jumpers in the achievement of power/strength tasks compared with endurance runners, as previously reported ${ }^{17,18}$.

Although our study has an apparent limitation of the sample size, our findings are relevant since the presence of DD homozygotes showed favors SJ performance in sprinters and jumpers compared to endurance, while ID heterozygotes increase SJ scores only sprinters, but not to jumpers' athletes. The presence of the DD genotype may 

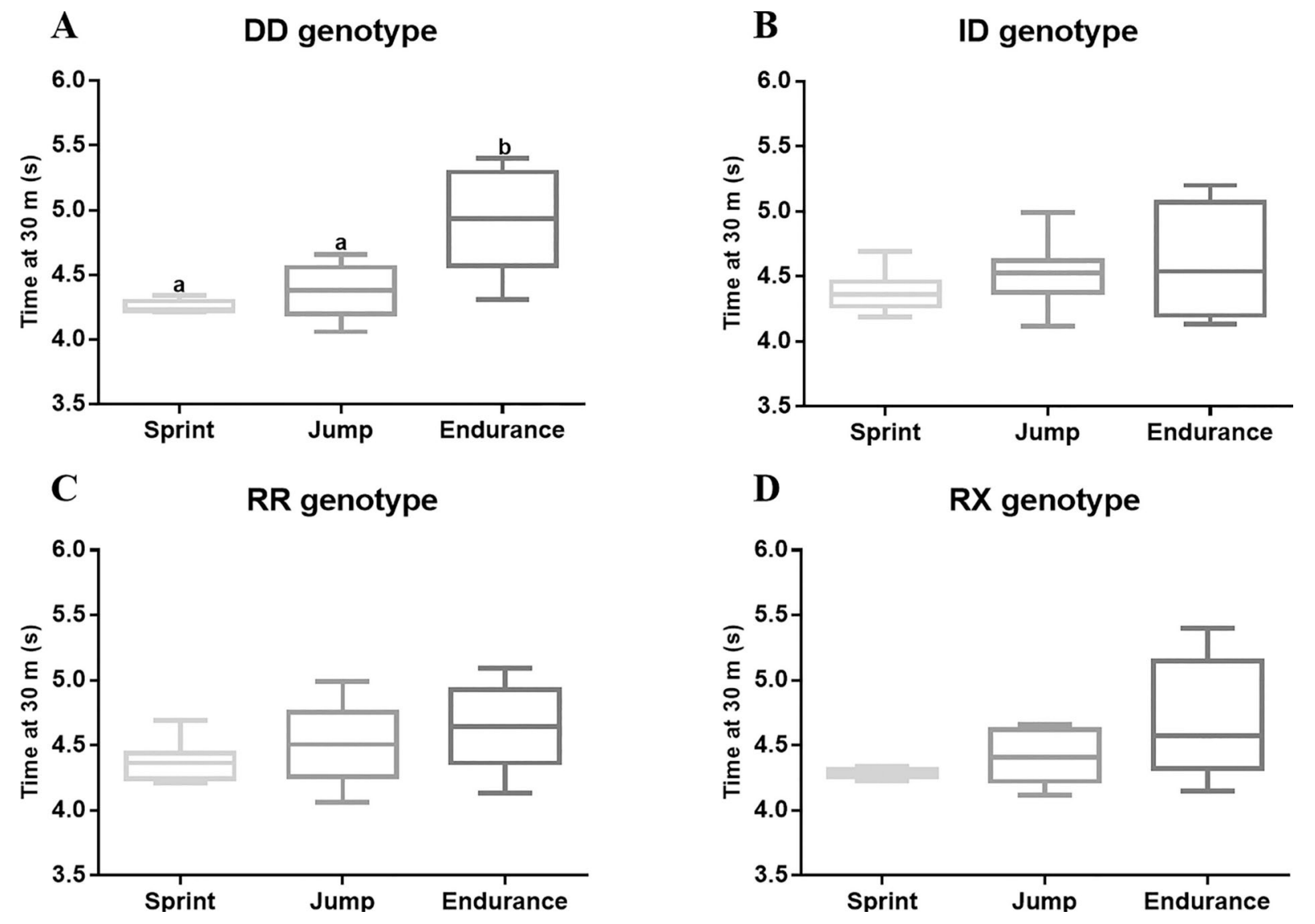

Figure 3 - Effect of ACE and ACTN3 gene variants on $30 \mathrm{~m}$ sprint in young talents. The DD genotype (a), ID genotype (b), RR genotype (c), and RX genotype (d). Different letters indicate significant differences between groups (one-way test (ANOVA) followed by Tukey's test, $p<0.05$ ).

be likely for the optimal generation of strength in jumpers. Loturco et al. (2015) ${ }^{29}$ showed that sprinters, jumpers, and throwers performed higher jumps than endurance athletes; therefore, differences in jump height reflect muscle fiber composition, neuromechanical properties, and trainingspecific adaptations across these athletes.

The SJ height was unchanged remain with RR homozygotes among sprinters, jumpers, and endurance runners. It is known that the performance of sprint/power athletes was associated with an elevated proportion of the $\mathrm{R}$ allele $\mathrm{e}^{27}$ and may be mainly related to the $\alpha$-actinin- 3 , the most-highly protein specialized of the $\alpha$-actinins family (in mammalian) ${ }^{28}$. However, studies showed that the RR genotype was more prevalent among sprinters/jumpers and weightlifters than the controls, it is considered essential for elite sprinting and jumping performance ${ }^{30}$. Thus, the RR genotype may be more related to specialized athletes (elite-level) due to training-related effects, but rather should not carry advantage for the non-specialized young population.

Besides, sprint performance of sprinters and jumpers with DD homozygotes showed a faster $30 \mathrm{~m}$ sprint time when compared to the endurance athletes. Sprinters are expected to have a metabolic advantage to carry out repe- ated contractions under a high metabolic flux. In this way, the $\mathrm{D}$ allele was found to demonstrate a higher percentage of muscle fiber type $\mathrm{II}^{26}$, characterized by a possible advantageous effect in power sports, including sprinters with higher D-allele frequency in running $\leq 200 \mathrm{~m}^{31}$. Like in the current study, previous research did not report this finding involving the jumpers' group. On the other hand, there was no possibility to verify a change in sprint performance between groups with ID, RR, and RX genotypes. It was shown that the ID heterozygotes did not seem to favor the athletes during $30 \mathrm{~m}$ sprint tests ${ }^{32}$, since the I allele in homozygosis or heterozygosis has shown a higher percentage of type I fibers/slow-twitch type fibers ${ }^{26}$. Despite jumpers' and sprinters' occurring naturally multi-joint movements in humans, differences in the angular velocities at the hip or knee joints showed distinct results for the same genotype (ID, RX, and RR) ${ }^{27,32}$. During sprint events, the rate of force development is influenced by multiple factors, such as muscle fiber types, synchronization of motor units, and tendon stiffness, which is a critical performance determinant in sports disciplines ${ }^{33}$. Thus, the use of tests with isokinetic (single-joint), jumps, and sprints (multi-joint) can better reveal the genotype-phenotype relationships ${ }^{32}$. 

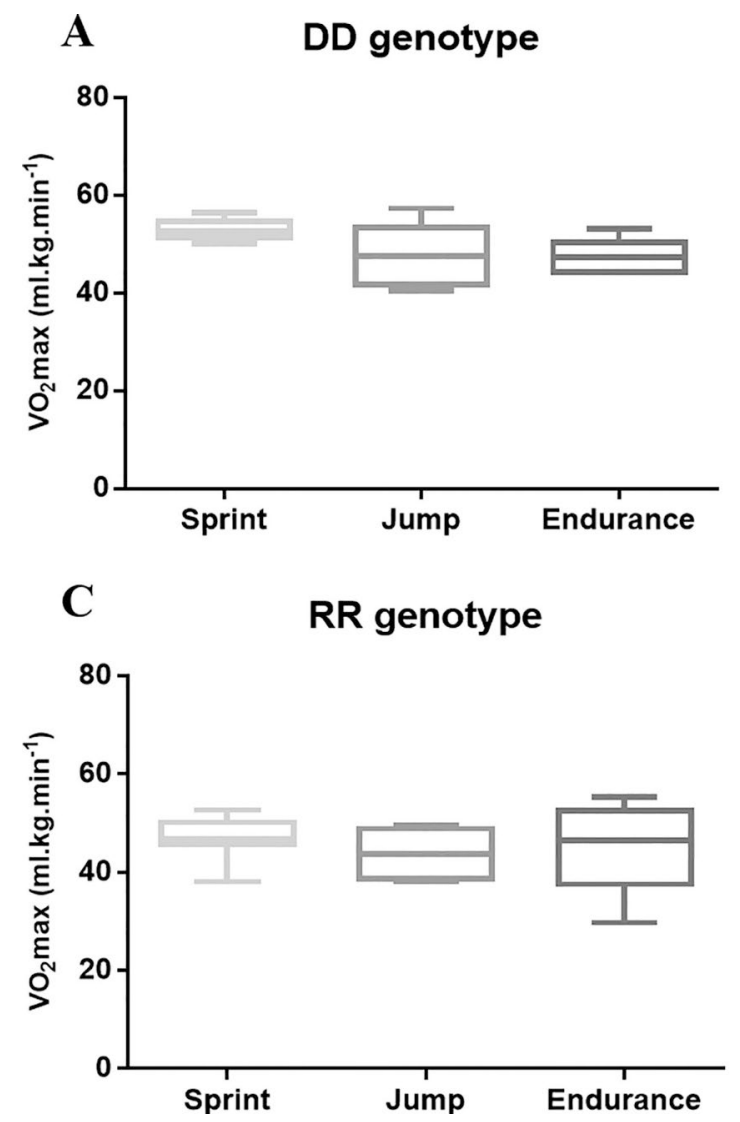

\section{B ID genotype}

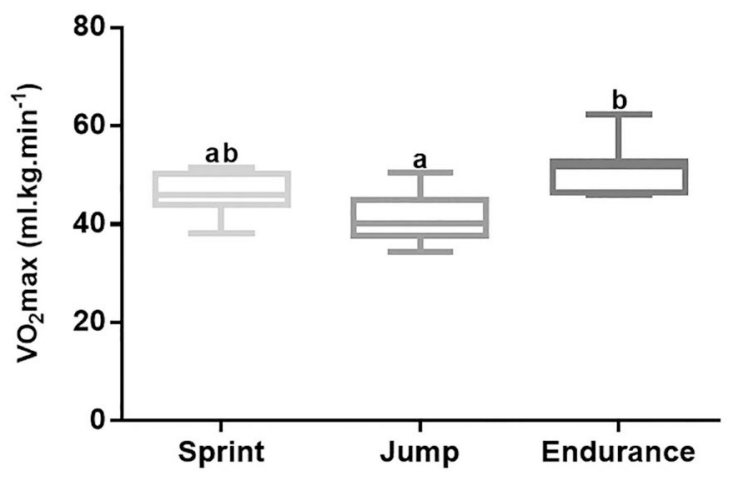

D RX genotype

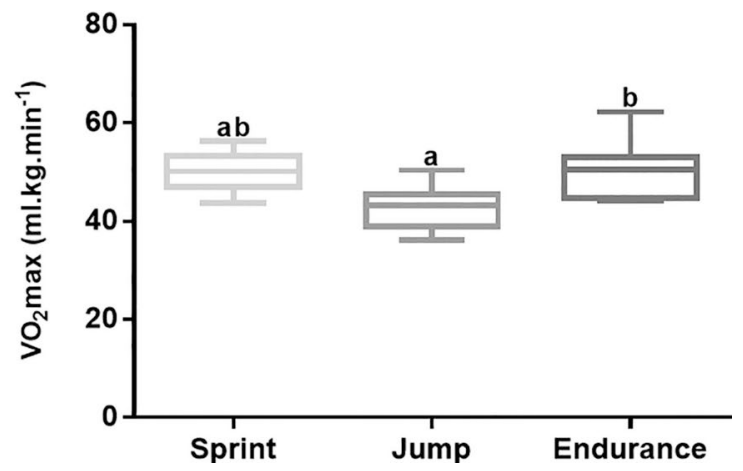

Figure 4 - Effect of ACE and ACTN3 gene variants on $\mathrm{VO}_{2 \max }$ in young talents. The DD genotype (a), ID genotype (b), RR genotype (c) and RX genotype (d). Different letters indicate significant differences between groups (one-way test (ANOVA) followed by Tukey's test, $\mathrm{p}<0.05$ ).

Both $\mathrm{X}$ and I alleles are related to endurance performance ${ }^{31,34}$. There has also evidence that an increased percentage of slow-twitch type I fibers are related to these alleles $^{26,35}$. Particularly, the performance of elite distance runners has been associated with a linear trend of increasing I allele frequency by distance $\operatorname{ran}^{31}$. Findings showed in other cohorts an excess of the D allele in the short distance athletes with an excess of the I allele in the middle-distance athletes $^{36}$. In our study, the presence of I (ID) and X (RX) alleles amongst the sprinters and endurance runners were associated with a better level of aerobic fitness $\left(\mathrm{VO}_{2 \max }\right)$. This data may be linked to an individual profile suitable to excel in both mixed (aerobic and anaerobic) and predominantly anaerobic sport disciplines. Higher aerobic fitness is an important requirement, but not determinant since $\mathrm{VO}_{2 \max }$ may be influenced by genetic and environmental variables with marked inter-individual response to training $^{37}$. Studies have shown no difference between I and $\mathrm{X}$ alleles, and their respective genotypes with $\mathrm{VO}_{2 \max }{ }^{35,38}$, emphasizing our finding of ID and RX genotypes to $\mathrm{VO}_{2 \max }$.

\section{Conclusion}

In summary, our pilot study concludes that both ACE DD and ACTN3 RX genotypes may benefit young talents in different sport disciplines that require sprint and power, while ACE ID and ACTN3 RX genotypes benefit endurance runners. Here, a priori, the $\mathrm{D}$ allele seems to be more important in the sports initiation, and it seems to present a definition of the sports phenotype. Whereas $\mathrm{R}$ allele seems to be a more "refined" or "specialized" gene, closely linked to the quality of the movement and that can be influenced by external factors, such as training.

\section{Acknowledgments}

The authors thank CAPES and CNPQ for scholarships.

\section{References}

1. Ahmetov II, Rogozkin VA. Genes, athlete status and training - an overview. Med Sport Sci. 2009;54:43-71. doi

2. MacArthur DG, North KN. Genes and human elite athletic performance. Human Genetics. 2005;116(5):331-9. doi

3. Tucker R, Santos-Concejero J, Collins M. The genetic basis for elite running performance. Br J Sports Med. 2013;47 (9):545-9. doi

4. Houweling PJ, Papadimitriou ID, Seto JT, Pérez LM, Coso $\mathrm{JD}$, North KN, et al. Is evolutionary loss our gain? The role of ACTN3 p.Arg577Ter (R577X) genotype in athletic per- 
formance, ageing, and disease. Hum Mutat. 2018;39 (12):1774-87. doi

5. Ma F, Yang Y, Li X, Zhou F, Gao C, Li M, et al. The association of sport performance with ACE and ACTN3 genetic polymorphisms: a systematic review and meta-analysis. PLoS One. 2013;8(1):e54685. doi

6. Yang N, MacArthur DG, Gulbin JP, Hahn AG, Beggs AH, Easteal S, et al. ACTN3 genotype is associated with human elite athletic performance. Am J Hum Genet. 2003;73 (3):627-31. doi

7. Enriquez J, Gullans S. Olympics: genetically enhanced Olympics are coming. Nature. 2012;487(7407):297. doi

8. Tharabenjasin P, Pabalan N, Jarjanazi H. Association of the ACTN3 R577X (rs1815739) polymorphism with elite power sports: a meta-analysis. PLoS One. 2019;14(5): e0217390. doi

9. Rigat B, Hubert C, Alhenc-Gelas F, Cambien F, Corvol P, Soubrier F. An insertion/deletion polymorphism in the angiotensin I-converting enzyme gene accounting for half the variance of serum enzyme levels. J Clin Invest. 1990;86 (4):1343-6. doi

10. Williams AG, Rayson MP, Jubb M, World M, Woods DR, Hayward M, et al. The ACE gene and muscle performance. Nature. 2000;403(6770):614. doi

11. Cambien F, Poirier O, Lecerf L, Evans A, Cambou JP, Arveiler D, et al. Deletion polymorphism in the gene for angiotensin-converting enzyme is a potent risk factor for myocardial infarction. Nature. 1992;359(6396):641-4. doi

12. Tiret L, Kee F, Poirier O, Nicaud V, Lecerf L, Evans A, et al. Deletion polymorphism in angiotensin-converting enzyme gene associated with parental history of myocardial infarction. Lancet. 1993;341(8851):991-2. doi

13. Gordon SE, Davis BS, Carlson CJ, Booth FW. ANG II is required for optimal overload-induced skeletal muscle hypertrophy. Am J Physiol Endocrinol Metab. 2001;280(1): E150-9. doi

14. John R, Dhillon MS, Dhillon S. Genetics and the elite athlete: our understanding in 2020. Indian J Orthop. 2020;54 (3):256-63. doi

15. Jeremic D, Zivanovic-Macuzic I, Vulovic M, Stevanovic J, Radovanovic D, Varjacic V, et al. Ace/Actn3 genetic polymorphisms and athletic performance of female soccer players'. Rev Bras Med Esporte 2019;25(1):35-9. doi

16. Orysiak J, Mazur-Różycka J, Busko K, Gajewski J, Szczepanska B, Malczewska-Lenczowska J. Individual and combined influence of ACE and ACTN3 genes on muscle phenotypes in Polish athletes. J Strength Cond Res. 2018;32 (10):2776-82. doi

17. Dionísio TJ, Thiengo CR, Brozoski DT, Dionísio EJ, Talamoni GA, Silva RB, et al. The influence of genetic polymorphisms on performance and cardiac and hemodynamic parameters among Brazilian soccer players. Appl Physiol Nutr Metab. 2017;42(6):596-604. doi

18. Jacob Y, Spiteri T, Hart NH, Anderton R. The potential role of genetic markers in talent identification and athlete assessment in elite sport. Sports. 2018;6(3):88. doi

19. Johnston K, Wattie N, Schorer J, Backer J. Talent identification in sport: a systematic review. Sports Med. 2018;48 (1):97-109. doi
20. Jiménez-Jiménez R, Cuevas MJ, Almar M, Lima E, GarcíaLópez D, De Paz JA, et al. Eccentric training impairs NF-кB activation and over-expression of inflammation-related genes induced by acute eccentric exercise in the elderly. Mech Ageing Dev. 2008;129(6):313-21. doi

21. Lindpaintner K, Pfeffer MA, Kreutz R, Stampfer MJ, Grodstein F, LaMotte F, et al. A prospective evaluation of an angiotensin-converting-enzyme gene polymorphism and the risk of ischemic heart disease. N Engl J Med. 1995;332 (11):706-11. doi

22. Shanmugam V, Sell KW, Saha BK. Mistyping ACE heterozygotes. Genome Res. 1993;3(2):120-1. doi

23. Bosco C, Mognoni P, Luhtanen P. Relationship between isokinetic performance and ballistic movement. Eur J Appl Physiol Occup Physiol. 1983;51(3):357-64. doi

24. Little T, Williams AG. Specificity of acceleration, maximum speed, and agility in professional soccer players. J Strength Cond Res. 2005;19(1):76-8. doi

25. Pallarés JG, Cerezuela-Espejo V, Morán-Navarro R, Martínez-Cava A, Conesa E, Courel-Ibáñez J. A new short track test to estimate the VO2max and maximal aerobic speed in well-trained runners. J Strength Cond Res. 2019;33 (5):1216-21. doi

26. Zhang B, Tanaka H, Shono N, Miura S, Kiyonaga A, Shindo $\mathrm{M}$, et al. The I allele of the angiotensin-converting enzyme gene is associated with an increased percentage of slowtwitch type I fibers in human skeletal muscle. Clin Genet. 2003;63(2):139-44. doi

27. Vincent B, De Bock K, Ramaekers M, Eede EV, Leempute MV, Hespel P, et al. ACTN3 (R577X) genotype is associated with fiber type distribution. Physiol Genomics. 2007;32(1):58-63. doi

28. MacArthur DG, North KN. A gene for speed? The evolution and function of $\alpha$-actinin-3. BioEssays. 2004;26(7):786-95. doi

29. Loturco I, Gil S, Laurino CFDS, Roschel H, Kobal R, Abad $\mathrm{CCC}$, et al. Differences in muscle mechanical properties between elite power and endurance athletes: a comparative study. J Strength Cond Res. 2015;29(6):1723-8. doi

30. Ben-Zaken S, Eliakim A, Nemet D, Meckel Y. Genetic variability among power athletes: the stronger vs the faster. J Strength Cond Res. 2019;33(6):1505-11. doi

31. Myerson S, Hemingway H, Budget R, Martin J, Humphries $\mathrm{S}$, Montgomery $\mathrm{H}$. Human angiotensin I-converting enzyme gene and endurance performance. J Appl Physiol. 1999;87 (4):1313-6. doi

32. Rodríguez-Romo G, Ruiz JR, Santiago C, Fiuza-Luces C, González-Freire M, Gómez-Gallego F, et al. Does the ACE I/D polymorphism, alone or in combination with the ACTN3 R577X polymorphism, influence muscle power phenotypes in young, non-athletic adults? Eur J Appl Physiol. 2010;110(6):1099-1106. doi

33. Perez-Gomez J, Rodriguez GV, Ara I, Olmedillas H, Chavarren J, González-Henriquez JJ, et al. Role of muscle mass on sprint performance: gender differences? Eur J Appl Physiol. 2008;102(6):685-94. doi

34. Niemi AK, Majamaa K. Mitochondrial DNA and CTN3 genotypes in Finnish elite endurance and sprint athletes. Eur J Hum Genet. 2005;13(8):965-9. doi 
35. Coso JD, Moreno V, Gutiérrez-Hellín J, Baltazar-Martins G, Ruíz-Moreno C, Aguilar-Navarro M, et al. ACTN3 R577X genotype and exercise phenotypes in recreational marathon runners. Genes (Basel). 2019;10(6):413 doi

36. Nazarov IB, Woods DR, Montgomery HE, Shneider OV, Kazakov VI, Tomilin NV, et al. The angiotensin-converting enzyme I/D polymorphism in Russian athletes. Eur J Hum Genet. 2001;9(10):797-801. doi

37. Mann TN, Lamberts RP, Lambert MI. High responders and low responders: Factors associated with individual variation in response to standardized training. Sports Med. 2014;44 (8):1113-24. doi

38. Goh KP, Chew K, Koh A, Guan M, Wong YS, Sum CF. The relationship between ACE gene ID polymorphism and aerobic capacity in Asian rugby players. Singapore Med J. 2009;50(10):997-1003.

\section{Corresponding author}

Pamela C. Da Rosa. Universidade Federal do Paraná, Departamento de Educação Física, Centro de Estudos da Performance Física, Curitiba, PR, Brazil.

E-mail: pamelacarvalhodarosa@gmail.com.

Manuscript received on March 4, 2021

Manuscript accepted on December 9, 2021

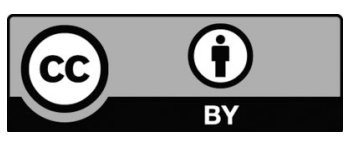

Motriz. The Journal of Physical Education. UNESP. Rio Claro, SP, Brazil - eISSN: 1980-6574 - under a license Creative Commons - Version 4.0 